\title{
Study on seismic performance of coupling beams between cast-in-situ and prefabricated frame shear wall
}

\author{
Chen Jiguang ${ }^{1,2, a}$, Liu Ling ${ }^{2, b}$ Zou Jianqi ${ }^{2, b}$
}

${ }^{1}$ Institute of Engineering Mechanics, China Earthquake Administration. Key Laboratory of Earthquake Engineering and Engineering Vibration, China Earthquake Administration ,Harbin 150080,China.

\section{${ }^{2}$ School of Civil Engineering, ChangChun Architecture and Civil Engineering college ,Changchun 130607, China. \\ a chenjiguang21@sina.com, b867844084@qq.com}

Keywords: prefabricated; cast-in-situ; coupling beam; mechanical properties

Abstract : Coupling beam is the first line of seismic defense. In order to study on seismic performance of coupling beams between cast-in-situ and prefabricated frame shear wall, based on finite element ABAQUS software analysis. The load-bearing process of 1 prefabricated coupling beam and 1 cast-in-situ coupling beam under low-cycle repeated load are simulated. The bearing capacity and seismic performance of two types is analyzed from the hysteresis curves, skeleton curves, energy dissipation coefficient and equivalent viscous damping coefficient and stiffness degradation, ductility coefficient .The simulation results were compared with two types, the results show: two types of coupling beam have good ductility and energy dissipation capacity. But the cast-in-situ is better than the prefabricated.

\section{Introduction}

In reinforced concrete frame-shear wall structure(FSW), coupling beam is the first line of seismic defense and plays a role in connecting wall limbs and transferring loads. Under earthquake action, the plastic hinge is formed on the ends of the beam, which uses the plastic hinge to dissipated the energy of the earthquake[1-3].With coupling beam in FSW, as shown in Fig1.Shear coupling beam(SCB) and the corresponding frame beam up to it, briefly called frame coupling beam(FCB), has a stage of cooperative working under horizontal load[4].So, the parallel double coupling beams with different width composed of SCB and FCB, briefly called double beams(DB), is taken as a research object. Meanwhile, a new type of assembly method is proposed of coupling beam in FSW, based on assembly method, the seismic performance of prefabricated is analyzed. In accordance with standards cast-in-situ coupling beam is designed .

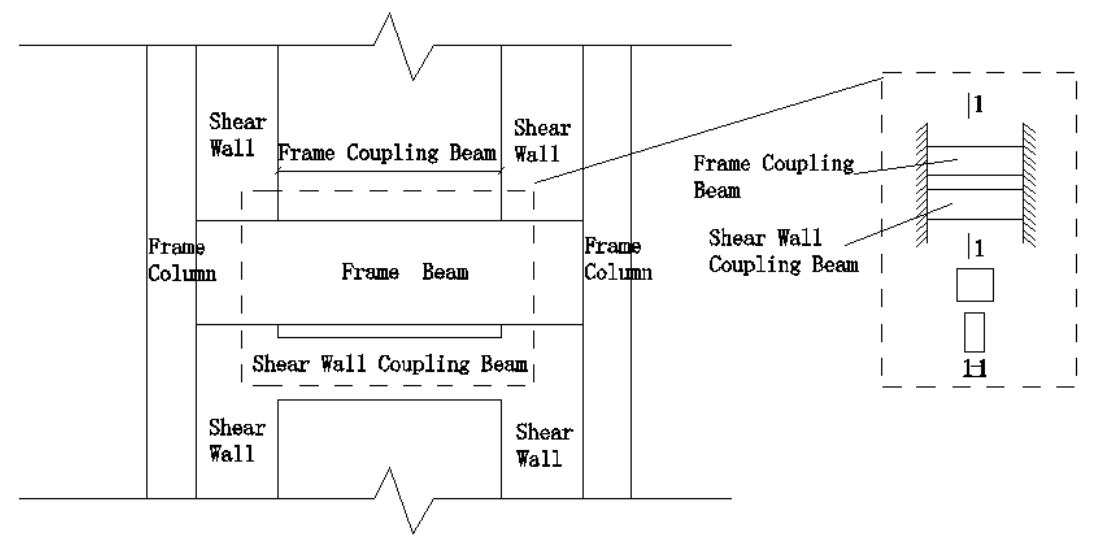

Fig1 Frame-shear wall structure layout

Finite element simulation method .The loading process of cast-in-situ and prefabricated are simulated by ABAQUS finite element software. In simulation: the stress-strain curve of the concrete is plastic damage model; Modulus of elasticity to take $3 \times 10^{4} \mathrm{~N} / \mathrm{mm}$, Poisson is 0.2 , the density of concrete is $2400 \mathrm{~kg} / \mathrm{m}^{3}$. The reinforcement adopts HRB335 and HRB400, the modulus of elasticity in 
yield is $1 \%$ of the initial modulus of elasticity, Poisson is 0.3 , the density of steel is $7850 \mathrm{~kg} / \mathrm{m}^{3}$,eight-node reduced integration of the three-dimensional solid elements (C3D8R) are used to simulate the concrete and upper and lower blocks. TRUSS elements are used to simulate steel. The friction coefficient of contact is 0.65 with the contact between the beam and the end block. In order to simulate the same loading and boundary conditions as the actual situation, the large stiffness of upper and lower block is built up on the two sides of two types coupling beams.A reference point RP1 is set in the upper block, coupling the RP1 with the end surface to make the reference point work with the end block, makes upper block can slid along horizontal direction and lower block along beam direction. The lower block is slid by releasing displacement of y-directions, internal and external plane rotation of the block is limited. The finite element model is shown as Fig.2. Newton-Raphson iteration method is adopted to solve the problem .
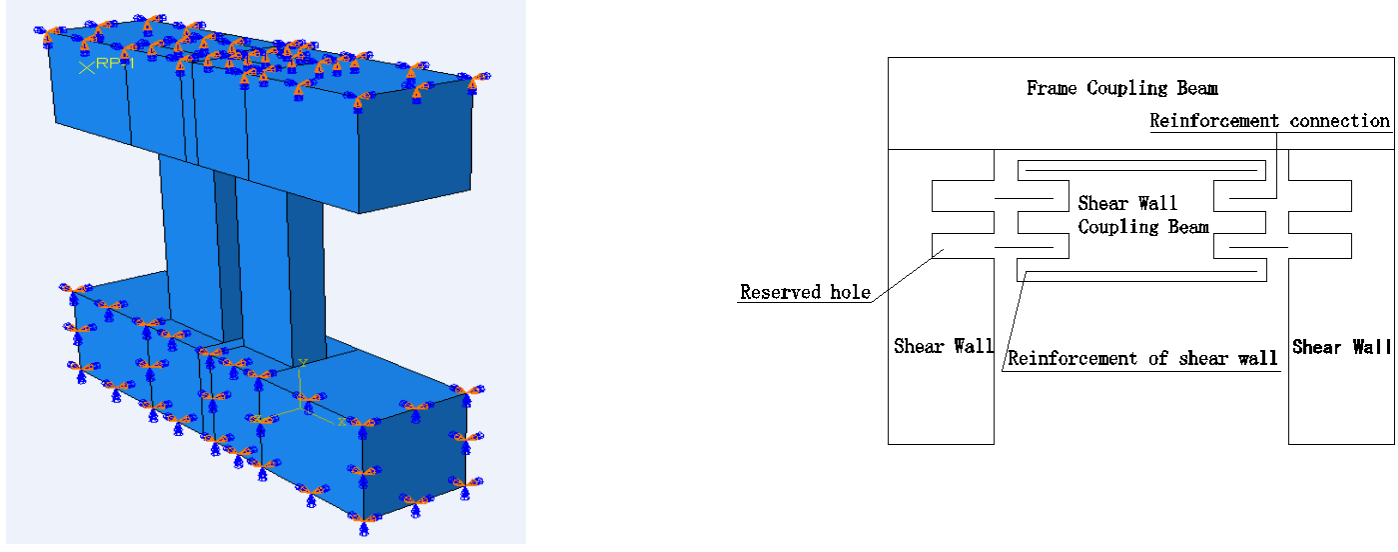

Fig.2Boundary condition and loading method

Fig.3 The assemble model of prefabricated

Assembly method of prefabricated coupling beam. At the end of prefabricated coupling beam, the connection position of the wall is divided. Prefabricated coupling beam and two pieces of prefabricated wall are fabricated, respectively. Prefabricated coupling beam and two pieces of prefabricated wall in the reserved hole. The spiral stirrups were set in the hole, and inside the hole equivalent reinforcement is installed. The micro expansion mortar is inserted into the reserved prefabricated coupling beam and two pieces of prefabricated wall with holes. The mortar makes equivalent reinforcing bars and two precast parts together. The assemble model of prefabricated is shown as Fig.3.

Seismic performance analysis of two types. Fig.4 and Fig5 are hysteresis curves of two types coupling beams. It can be seen from Fig 5 that the prefabricated are pinching and the hysteresis curves turn from a spindle shape into a bow shape. But the hysteresis loop is full, skeleton curve is formed by connecting the peak points of the load-displacement of each cycle[5].Fig.6 and Fig7 are the skeleton curve of two types.It can be seen from the curves, when the displacement is not very large, the bearing capacity increase gradually. This is because the two types are the elastic stage. As the displacement increases gradually, the bearing capacity of prefabricated decreases gradually but the pace of decline is not very fast.

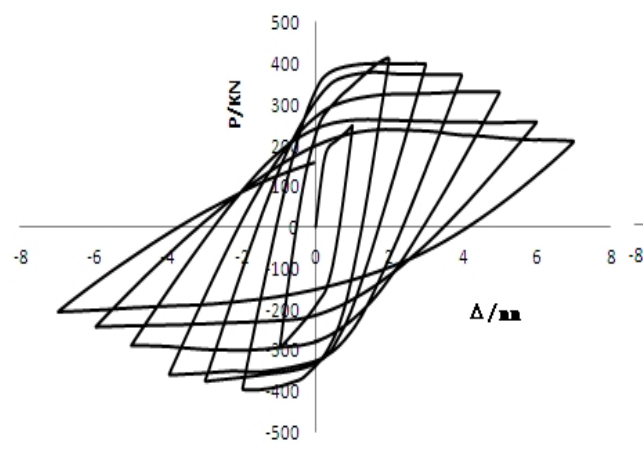

Fig 4 Cast-in-situ hysteresis curves

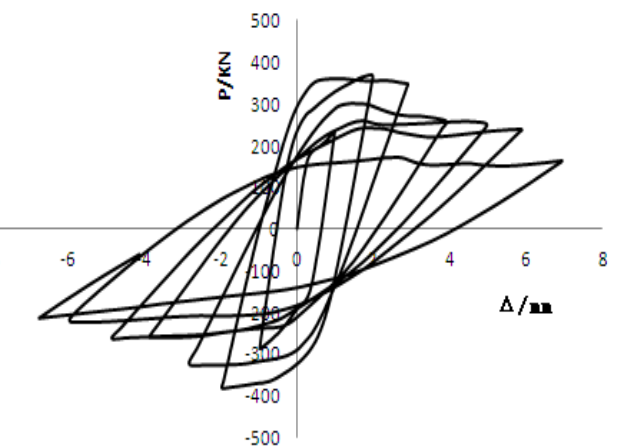

Fig 5 Prefabricated hysteresis curves 


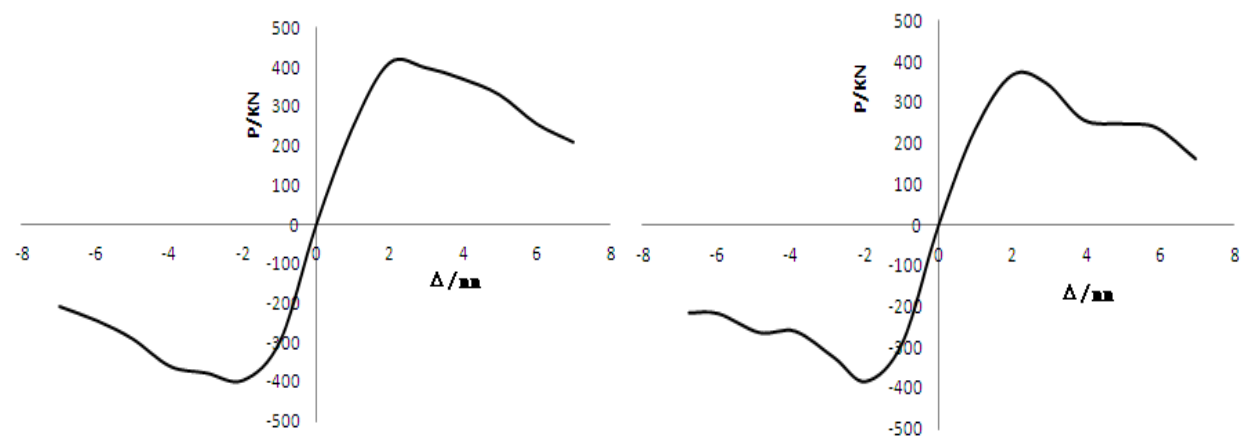

Fig 6 Cast-in-situ skeleton curves

Fig 7 Prefabricated skeleton curves

Ductility factor of two types. Ductility is used to measure the bearing capacity of inelastic deformation of structure or component before they are destructed. In seismic action, ductility is an important index, which is the purpose of seismic design is to control the plastic deformation of the structure or components to prevent serious damage or collapse of the structure or components. It is generally believed that ductility factor of concrete structure is not less than 2.From calculation, yield displacement is $2 \mathrm{~mm}$, limit displacement is $4.5 \mathrm{~mm}$, The ductility factors of prefabricated is calculated ,the result value is 2.25 . but cast-in-situ yield is $1.8 \mathrm{~mm}$,limit displacement is $4.3 \mathrm{~mm}$,the ductility is 2.38 .

Energy dissipation of two types. Under low cycle reciprocating load, the joint absorbs energy when loading and releases energy when unloading, which forms a cycle [6-7], shown as Fig. 8. Energy dissipation factor $\left(E_{c}\right)$ is the ratio of elastic energy and the total energy, shown as Eq.1. In Eq.1, $S$ represents the subscript letters corresponding area of the siege. Equivalent viscous damping coefficient $\left(h_{e}\right)$ is the ratio of $E_{c}$ and $2 \pi$, shown as Eq.2. Both of them can be used to measure the energy dissipation of structural members. From calculation, the dissipation coefficient of prefabricated is 1.9, and the equivalent viscous coefficient of it is 0.3 , but dissipation coefficient of cast-in-situ is 0.33 , and the equivalent viscous coefficient of it is 2.09 .

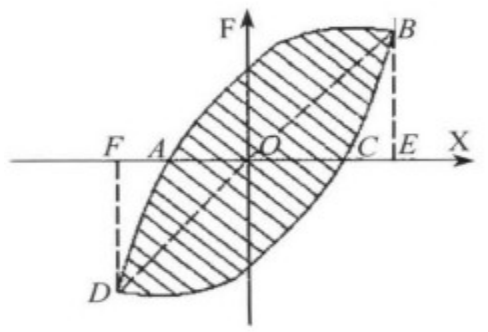

$$
\begin{gathered}
E_{C}=\frac{S_{A B C D}}{S_{\text {OFD }}+S_{\text {OEB }}} \\
h_{e}=E_{C} / 2 \pi \quad \text { ( Eq. }
\end{gathered}
$$

Fig.8 Hysteresis loop back sketch

Stiffness degradation of two types. The stiffness of the structure decreases with the increase of the displacement amplitude under low-cycle repeated load. Stiffness calculation of specimens is shown Fig9. $\mathrm{Ki}$ is the coefficient of stiffness degradation, $\mathrm{PA} 、 \mathrm{~PB}$ are peak points of load values, $\Delta \mathrm{A}, \Delta \mathrm{B}$ are peak points of displacement. From calculation, two types of coupling beams stiffness degradation are drawn. shown as Fig.10、 Fig11.

Compared cast-in-situ with prefabricated coupling beams .A new type of assembly method is proposed of coupling beam. Based on finite element ABAQUS software analysis, The load-bearing process of 1 prefabricated coupling beam and 1 cast-in-situ coupling beam under low-cycle repeated load are simulated.Fig12 and Fig13 are shown compared cast-in-situ with prefabricated From calculation, ductility coefficient is different $2.2 \%$,energy dissipation coefficient is different $9 \%$ and equivalent viscous damping coefficient is different $9 \%$, and stiffness degradation trend is similar, but cast-in-situ initial stiffness higher than prefabricated type. It can be seen from results that new type of assembly method is feasible. 


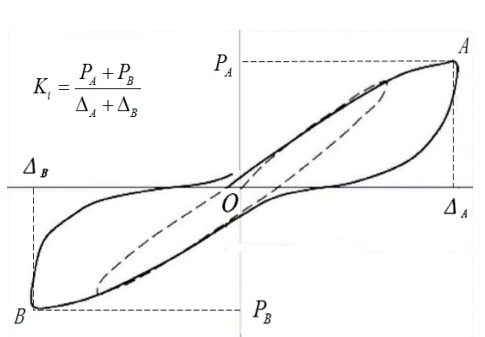

Fig.9 Stiffness calculation of specimens

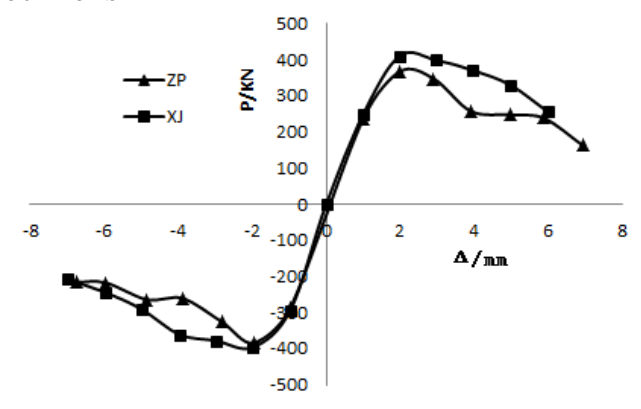

Fig 12 compare skeleton curves

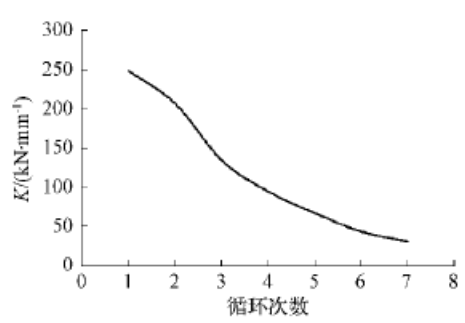

Fig.10 Stiffness degradation of cast-in-situ

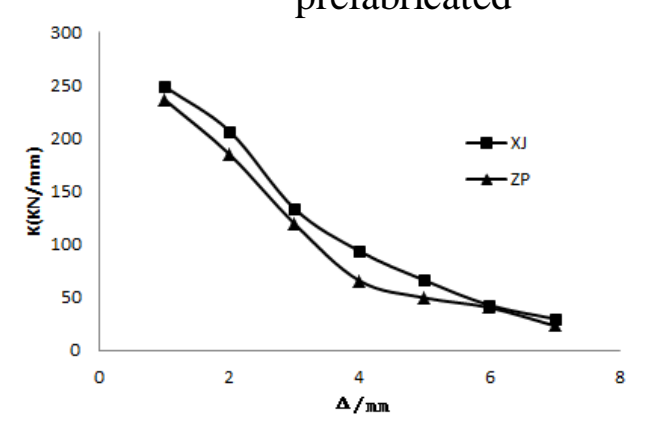

Fig 13 compare stiffness degradation

\section{Conclusions}

1、From calculation, two types of ductility coefficient is different $2.2 \%$,energy dissipation coefficient is different $9 \%$ and equivalent viscous damping coefficient is different $9 \%$, and stiffness degradation trend is similar, but cast-in-situ initial stiffness higher than prefabricated type. The new type of assembly method has good energy dissipation performance.

2、Although the finite element simulation analysis of two types coupling beams, but concept design and experimental research are also needed, which is the future work.

\section{Acknowledgements}

This work was financially supported by the Scientific Research Fund of the Institute of Engineering Mechanics, CEA (2016A06) and Scientific Research Fund of Jilin Provincial Education Department ( JJKH20171036KJ )

\section{References}

[1] WJ Zhao,Q Zhong,LG Jia , YG Zhang . Journal of Shenyang Jianzhu University , 2015 , 31 ( 2 ) : 276-285.

[2] JX Chen. YW. Liu, JR. Yang and X Xiao .Advanced materials research ,2014,919-921:981-988.

[3] M Li, JG Chen and WJ Zhao.ICDMA2013,1156-1159.

[4] M Li ,LG Wang, YQ Wang, W Tao ,LG Shan ,JG Chen. Industrial Construction.(S1)2015 .391-394.

[5] (JGJ 101-96), China Architecture \& Building Press, 1997.

[6] XN Lu ,Y Yu. . Structural Engineering and Mechanics 2000 .9 (4) .365-374.

[7] Amit H. Varma , James M. Ricles , Richard Sause, et al ..Journal of Constructional Steel Research ,2002,58 (5):725-758. 